\title{
The Bradford and Airedale Experience with Telemedicine
}

\section{Shahid Ali}

Telehealth services promise substantial benefits for patients, physicians, and payers. Yet, while there has been some growth in adoption, much more is needed for scalable deployment to achieve more meaningful impact across the healthcare system.

For example, the UK Preventative Technology Grant, launched in 2004, was designed to encourage adoption of telecare and telehealth by creating an environment in which industry could flourish. ${ }^{1}$ Despite this effort, uptake of telemedicine has been described as "sluggish," with the UK falling behind other countries such as the U.S., Australia, India and China in exploiting them. ${ }^{2}$ This is interesting when one considers that in the U.S., telehealth constitutes less than $1 \%$ of ambulatory visits. ${ }^{3}$

For physicians with large and growing general practices (both existing patients due to increased longevity and new patients), the key issue is how to provide and improve patient-centered care and manage increasing demand for services. And here there is the opportunity to be work smarter using digital health technology to provide patientcentered care, rather than resorting to increased staffing and larger facilities as the default option. This can be applied through an integrated model that permits patients greater access to medical care in their homes or care centers, with ready access to econsultations and triage to higher levels of care as needed. The objective of this report is to present the benefits and cost savings associated with specific hospital outcomes as a result of telemedicine interactions between a care hub (hospital) and remote care homes (dementia, nursing, and residential care) ranging from 40 to 100 beds in Yorkshire, England, and how physicians can work 'more smartly' to manage demand and release time for practice.

\section{Methods}

An initial pilot study was conducted at Airedale (i.e., the hub), an NHS hospital and community services trust, providing acute, elective, specialist, and community care for 
over 200,000 people in an area covering 700 square miles within Yorkshire and Lancashire.

Data obtained over 12 months [2014 to 2015] were compared to medical records from one year earlier [2014]. Outcomes included changes in hospital admissions, length of hospitalization, and number of hospital bed days.

\section{Results}

A total of 1377 patient calls were studied over 12 months. Table 1 shows that hospital admissions declined by $45 \%$ (227 to 125). Mean length of stay was reduced $30 \%$ from 12.4 to 8.7 days, while mean bed days declined $60 \%$ (3044 to 1208 days).

Table 1. Changes related to hospital utilization before and after introduction of telemedicine.

\begin{tabular}{|c|c|c|c|}
\hline Outcomes & $\begin{array}{c}\text { Pre- } \\
\text { Telemedicine }\end{array}$ & $\begin{array}{c}\text { Post- } \\
\text { Telemedicine }\end{array}$ & Change \\
\hline Admissions (n) & 227 & 125 & $-45 \%$ \\
\hline Length of Stay (d) & 12.4 & 8.7 & $-30 \%$ \\
\hline Bed Days (d) & 3044 & 1208 & $-60 \%$ \\
\hline
\end{tabular}

\section{Discussion}

The results suggested that through implementation of a telemedicine program, positive results on hospital utilization are recognized within one year.

In the case of Airedale, the key to success appears to be creation of a telemedicine hub that connects to care homes $24 / 7$, particularly in the evening when medical practices are closed. The hub makes it possible for care home patients and care givers to contact the hub for advice. Information and necessary care is provided by general practitioners and specialists when necessary.

The data reported here support the value of this service in terms of hospital utilization. These telemedicine services have now expanded to 475 care homes supporting $>18000$ 
patients in the region and beyond, as part of the national Enhanced Health in Care Homes Vanguards programme. ${ }^{4}$

\section{Follow-up}

Given the initial impact of telemedicine in the region, the service has now expanded to include 475 care homes and has also providing a triage service for GP visits. The goals of this programme are to: improve the patient experience, manage patient flows, reduce costs of services delivered, and identify ways to reduce inappropriate demands on services and minimize unproductive physician travel time. The impact on healthcare services can be substantial as telemedicine services are used at scale.

\section{Healthcare Services}

Over one month, the availability of telemedicine has resulted in one less ambulance service call per care home per month. The cost of a roundtrip ambulance call is approximately $£ 230$ (\$287), with a resultant savings of $£ 200,000(\$ 250,000)$ for service to approximately 70 care homes ( 3570 patients).

There has been one less A\&E attendance per care home per month. At a cost of about $£ 126$ (\$157) per month per care home, the savings come to about $£ 10,000$ ( $\$ 1240)$ based on approximately 120 attendances.

Regarding non-elective admissions per care home per month, each hospital admission costs the NHS $£ 2,258$ ( $\$ 2800$ ), for a total savings of $£ 1,257,000 \$ 1560$ ), based on approximately 550 admissions saved.

\section{Physician Time Savings}

As might be expected, telemedicine offers an opportunity for better use of a physician's time, with resulting cost savings. Physicians receive one or more requests each day to go to a care home to consult with a patient. In the author's experience, each call to a care homes can take about an hour in travel and face-to-face patient assessment and treatment. 
Based on 7 years of experience in telemedicine, the author's visits to care homes have been reduced $70 \%$ compared to practices that do not have the availability of telemedicine. To enhance the patient experience and to help save clinician time, this service is now being expanded for all patients registered with the practice who wish to have telemedicine consultations rather than face-to-face consultation. The significance of this time savings is amplified by a 2015 Deloitte report predicting the number of faceto-face consultations with general practitioners in the UK is likely to double over the next two decades, with 433 million consultations predicted annually. ${ }^{5}$

Moreover, the ability to reduce face-to-face patient interactions through telemedicine may become of greater interest to patients, because of an ongoing debate in the UK over charging patients directly for doctor visits. A survey, carried out by the trade magazine Pulse, found that $51 \%$ of general practitioners supported fees ranging from $£ 5$ (\$6) to £25 (\$31) per appointment. ${ }^{5}$ Although for most patients this amounts to a small charge in terms of cost, from an emotionally and entitlement perspective it is significant in a country where the cost of healthcare has been covered by the government.

\section{Conclusion}

It was predicted more than a decade ago that the "growth and integration of information and communication technologies into healthcare delivery holds great potential for patients, providers and payers." Then, the most difficult question to answer was "When will telemedicine become part of the standard of care?"6

Greater detail in assessment of cost and time savings in the Bradford and Airedale experience will be published in the future. For patients, providers, and payers in Yorkshire, Lancashire and the UK, the time to continue to grow telemedicine as the standard of care is now. 


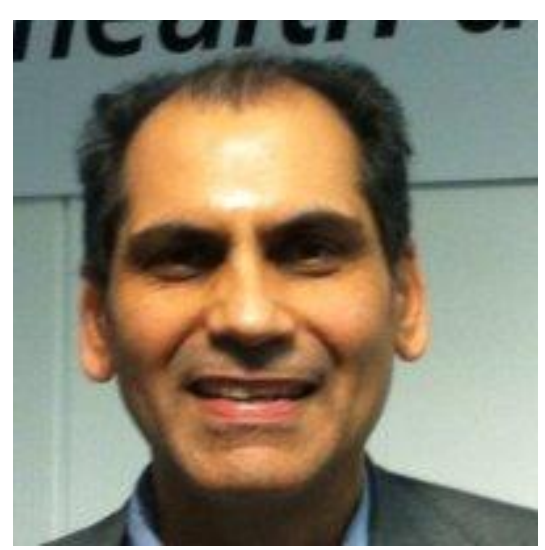

Page 5 of 6

Shahid Ali, BSc, MBChB, PhD, FICR, FRCP is a clinical leader with strategic vision and a passion to improve services and achieve better health outcomes for patients. He works as a general practitioner specialist, and has held senior NHS management roles at local and regional levels and as a National Clinical Leader. He is co-founder and Director of Dynamic Health Systems. Currently he is working on several work streams including empowering and enabling patient-centred care using technology, integration of services across pathways and intelligence for commissioning. Shahid is Professor of Digital Health in the University of Salford.

\section{References}

1. Building telecare in England, Department of Health, 2005,

2. Lakhani N. Britain lags behind in the telemedicine revolution. Independent. 2010. URL: http://www.independent.co.uk/life-style/health-and-families/healthnews/britain-lags-behind-in-the-telemedicine-revolution-2158120.html. Accessed 2/17/17.

3. Prewitt E. Q\&A: How telehealth is just getting started. NEJM Catalyst. 2016. URL: http://catalyst.nejm.org/qa-telehealth-technology-just-getting-started/. Accessed 2/16/17.

4. Enhanced healthcare in homes vanguards. NHS England. URL: https://www.england.nhs.uk/ourwork/new-care-models/vanguards/caremodels/care-homes-sites/. Accessed 2/26/17.

5. Cooper C. $£ 25$ to see your GP: Majority of doctors want to charge patients for routine appointments. Independent. 2013. URL:

http://www.independent.co.uk/life-style/health-and-families/health-news/25-to- 
see-your-gp-majority-of-doctors-want-to-charge-patients-for-routine-

appointments-8732498.html. Accessed 2/16/17.

6. Heinzelmann PJ, Lugn NE, Kevdar JC. Telemedicine in the future. J Telemed Telecare 2005;11:384-390. URL:

http://journals.sagepub.com/doi/pdf/10.1177/1357633X0501100802

Category: research

Tags: admissions, Airedale, bed days, Bradford, how telehealth enhances the doctor patient relationship, length of stay, NHS hospital and community services trust, Shahid Ali, telemedicine, time-savings, telemedicine process improvement, telemedicine program implementation, telemedicine remote health, what is telemedicine and how does it work 